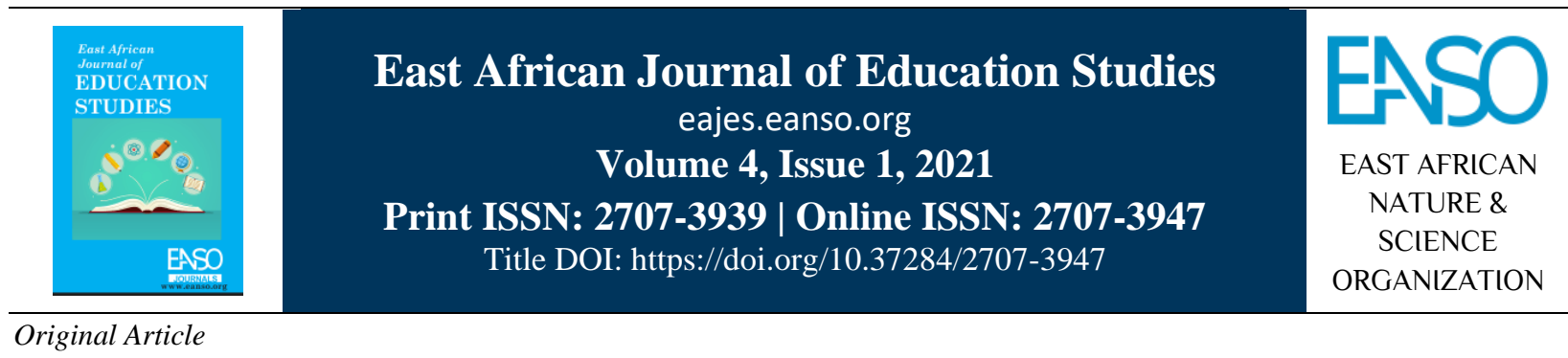

\title{
Supervisors Responses on Preparation of Schemes of Work During Teaching Practice in Public Universities in Eldoret, Kenya.
}

\author{
Dr. Margaret C. Kimwarey, $P h D^{1}$ \\ ${ }^{1}$ Moi University, P. O. Box 3900-30100, Eldoret, Kenya. \\ * Author for Correspondence Email: maggiekimwarey@yahoo.com.
}

Article DOI: https://doi.org/10.37284/eajes.4.1.495

\section{Date Published: ABSTRACT}

06 December 2021 Teacher education worldwide has been recognized as an important sector of education whose role is to prepare prospective teachers with the requisite

Keywords: knowledge, skill and attitude for the achievement of quality education. Lately, it has been given prominence because its end result is expected to become the strength of

Teacher change for sustainable development. The purpose of this study was to explore

Education,

Quality,

Preparation,

Scheme of Work,

Supervisors. supervisors' responses on the preparation of the scheme of work during teaching practice. The objectives of the study were to examine the scheme of work prepared by student teachers and to determine supervisors' responses on student teachers' preparation of scheme of work. The study was guided by the social cognitive theory. The study was based on the constructivist-interpretivism paradigm and adopted the qualitative approach. The research design was a descriptive survey that used document and content analysis. The sample size comprised student teachers on teaching practice and their supervisors. Data collection instruments included Lesson Observation Forms and documents where data was collected, sorted, categorized and coded as per a supervisor. Data analysis was done from the themes, forming patterns and presented thematically. The results of the study showed that student teachers' preparation of the scheme of work was not uniform. While other student teachers were able to develop a well-presented scheme of work, others were unable to present the expected as per the requirements offered during training. Anomalies noted specifically were on filling of the components which failed to show a relationship between one and another. The results of the study form a basis for refocusing on training bit on the preparation of the scheme of work. The results will benefit all stakeholders' teacher trainers, the department of curriculum and instruction, KICD and the Ministry of Education at all levels, especially those tasked with the training of teachers.

89 This work is licensed under a Creative Commons Attribution 4.0 International License. 


\section{APA CITATION}

Kimwarey, M. C. (2021). Supervisors Responses on Preparation of Schemes of Work During Teaching Practice in Public Universities in Eldoret, Kenya. East African Journal of Education Studies, 4(1), 89-97. https://doi.org/10.37284/eajes.4.1.495.

\section{CHICAGO CITATION}

Kimwarey, Margaret C. 2021. "Supervisors Responses on Preparation of Schemes of Work During Teaching Practice in Public Universities in Eldoret, Kenya”. East African Journal of Education Studies 4 (1), 89-97. https://doi.org/10.37284/eajes.4.1.495.

\section{HARVARD CITATION}

Kimwarey, M. C. (2021) "Supervisors Responses on Preparation of Schemes of Work During Teaching Practice in Public Universities in Eldoret, Kenya", East African Journal of Education Studies, 4(1), pp. 89-97. doi: 10.37284/eajes.4.1.495.

\section{IEEE CITATION}

M. C. Kimwarey, "Supervisors Responses on Preparation of Schemes of Work During Teaching Practice in Public Universities in Eldoret, Kenya”, EAJES, vol. 4, no. 1, pp. 89-97, Dec. 2021.

\section{MLA CITATION}

Kimwarey, Margaret C. "Supervisors Responses on Preparation of Schemes of Work During Teaching Practice in Public Universities in Eldoret, Kenya". East African Journal of Education Studies, Vol. 4, no. 1, Dec. 2021, pp. 89-97, doi:10.37284/eajes.4.1. 495.

\section{INTRODUCTION}

A higher percentage of countries worldwide recognize teacher education as an important component for the achievement of quality education. Its role includes providing pre-service teacher development on professional competencies (European Commission, 2013; Cochran-Smith \& Villegas, 2016). It is through it that prospective teachers are equipped with professional knowledge, teaching skills and ethical orientations for the effective performance of their duties and in the development of their society. This makes teacher education to be recognized as a rational practice that helps in the realization of the aims of education which include, among others to promote social, economic, technological and industrial needs for national development, promote individual development and self-fulfilment.

Through education, an opportunity for nurturing, developing and shaping individual abilities and behaviour is provided and from it, learners are made aware of the purpose of schooling as the intended outcome provides a foundation and shape of their future roles. Scholars such as Bishop (1985) see education as a purposeful activity. Owing to these aims and the importance of education, teacher training has been given prominence because it is only from this that comprehensive, equitable and quality education can become a vibrant instrument and strength of change for sustainable development. The attainment of these calls for adopting professionalism in teaching where planning, implementation, and evaluation are done in certain determined ways. This study looks at the planning aspect towards actual practice where the writer delved into the preparation of the schemes of work from the syllabus, a critical foundation for successful instruction. When developing the schemes of work, planning components gives the direction of how the lesson plan will be prepared and all activities involved during instruction. Therefore, the emphasis on the teacher preparation process accounts for the relevance and value the teacher transfers to the real classroom.

\section{Statement of the Problem}

Tatto et al. (2012), Gitomer and Zisk (2015) aver that determining teacher knowledge and skill as part of teachers' professional competence is important. This has made it a research topic during the last decades because teaching is a complex activity that requires systematic training and assessment of the extent to which a student-teacher is capable of linking theory into practice. In order to ascertain these linkages, student teachers in their third year of Bachelor of Education Degree course are posted to practice the skills learnt, an exercise which includes planning, preparation and implementation of teaching. This point rests on the fact that a successful formal teaching and learning process requires preparation which includes; development of the objectives, selection and sequencing of learning content and methodologies, proper selection and arrangement of the teaching items or materials, identification of teacher and learner 
activities and establishing the relevant reference materials and assessment strategies. Where this is done at the onset, future direction on the preparation of further documents will be enhanced.

However, from preliminary informal talk and experience, the writer established that a number of scenarios surrounded the preparation of the professional documents. As for this study, the preparation of the scheme of work showed that a number of student teachers, either personally prepared, used a commercially prepared scheme of work or even borrowed from their friends. Where the latter two situations occur, the essence of individual preparation for knowledge and skill acquisition is compromised. Developing professional documents requires the student teachers to link their professional knowledge to a concrete learning group which they are going to teach (Hall \& Smith 2006). Where this step is skipped, the writer ponders whether the novice teachers would manage to link their theoretical knowledge to practical problems of preparing the professional documents. On the basis of this, a study of the preparation of the scheme of work was necessary and from the lens of university supervisors' status, then informed the need for future action. Observation remarks on the preparation of professional documents such as the scheme of work play a central role in teaching practice in general and particularly in the professional life of student-teachers.

While numerous researches have been done on student-teacher experiences during teaching practice in totality, limited research has been done on supervisors' responses on the preparation of the scheme of work which is core in teacher preparation for instruction. Therefore, the need to ascertain the extent and application of required skill in preparation of the scheme of work and supervisors' responses towards this was seen to be unavoidable.

\section{Purpose of the Study}

The purpose of this study is to explore the supervisors' responses on the preparation of the scheme of work during teaching practice. The objectives of the study were to examine the scheme of work prepared by student teachers during teaching practice and to determine supervisors' responses on student teachers' preparation of scheme of work during teaching practice. The study was guided by the following research question: What responses were provided by supervisors on the preparation of the scheme of work by student teachers during teaching practice?

Subsidiary questions were:

- How did student-teacher prepare the scheme of work during teaching practice?

- What were the supervisors' responses on the prepared scheme of work during teaching practice?

\section{Justification of the Study}

The teaching profession requires that individuals trained in this field must exemplify practices and skills that facilitate instruction to learners at any level of education. It is the reason that teacher training forms a very important stage specifically as it provides a linkage between theory and practice. The latter is commonly referred to as practicum or teaching practice, a climax in the teacher training program. It is during this period that student teachers are assessed by university supervisors to determine their performance in terms of planning and implementation of the curriculum as per the school calendar. Through this period, monitoring, mentorship and assessment is done making it the core or the heart of teacher training as it provides data on student teachers performance, a form of feedback either forward or feed-forward (Hattie \& Timperley, 2007). In support of this, Copland (2010) avers that the central component of the teaching practice is the feedback offered to the student-teacher by an experienced teacher with the purpose of determining the situation as it is and reflecting on performance. The recommendations given form a basis for guidance, amendments or corrections and also gives room for clarifications, suggestions or advice. Through supervisory feedback, student teachers are assisted in developing the tacit aspects of professional competence and strong foundations of professional knowledge, conduct and tools for ongoing or future independent professional development. This rigorous exercise ends up shaping an individual and prepares one for a fruitful instructional process geared towards providing quality and sustainable education. 


\section{Limitation of the Study}

As mentioned, the responses sought by the study were limited to the preparation of the scheme of work. To ascertain whether the competencies were adopted and incorporated or not a scenario was noted where novice teachers purported to have individually developed, others copied or photocopied or even transferred from the commercially provided scheme of work. This matter was left to be determined by the supervisors. Secondly, the student teachers having been posted to a new environment may have difficulties in diagnosing student needs and their prior knowledge. Thirdly, student teachers first experience to be exposed to actual practice, the issues of nervousness on their intentions and exposure to supervision may compromise their thought and action. Fourth, the writing of the scheme of work by student teachers may not necessarily have captured and wrote down all their planning decision (Borko \& Livingston, 1989). Writers experience shows that some student teachers may present what they did not prepare, which may not give a true picture. However, this study seeks to determine the situation as it was so as to provide the much-needed recommendations.

\section{The Scope and the Significance of the Study}

The scope of the study was composed of studentteachers on teaching practice, university supervisors and schools where they have been posted. Secondly, supervisors and their student teachers from one of the zones, among others approved for teaching practice by university management and thirdly, all schools within the zone were considered because they have similar characteristics.

Teacher education is an important component in professional development which helps realize the achievement of quality education. With the aim of preparing highly qualified teachers, supporting preservice teachers' development on professional competence makes it an important research topic during the last few decades. Through teacher education, the overall aims of education are achieved such as to promote social, economic, technological and industrial needs for national development, promote individual development and self-fulfilment among others. Education also provides a foundation for technological and industrial development, a vibrant instrument and strength of change for sustainable development. Therefore, professional development forms a critical and effective strategy for the attainment of quality education.

To realize the purpose and intention of teacher education, the issues of planning for instruction, specifically the scheme of work before instruction from the officially provided syllabus (KIE, 2006), enables the student teachers to link their professional knowledge to a concrete learning group (Hall \& Smith 2006). Where this step is skipped, the writer ponders whether the novice teachers manage to link their theoretical knowledge to practice. While numerous researches have been done on student-teacher experiences during teaching practice in totality, limited research has been done on supervisors' responses on student-teacher preparation of the scheme of work. Therefore, this study has come at such a time when supervisors are expected to conform to quality assurance standards on assessment so that the end result is a qualified teacher with requisite professional knowledge, skills and attitude. The data collected will inform on the status of preparation of scheme of work which is hoped to bring into light the situation as it is for future action.

The results will also benefit all the policymakers and stakeholders such as the Ministry of Education and Kenya Institute of Curriculum Development, County Director of Education through County Quality Assurance staff on whether all schools have the required document for developing the professional documents.

\section{Theoretical Framework}

The study was guided by social cognitive theory, which proposes that human behaviour is learnt through observation and modelling (Bandura, 1986). Teacher training provides the student teachers with the rich ground for the acquisition of knowledge in theory and practice using approved documents such as the Lesson Observation Form (LOF), which allows for observation, assessment and modeling

\section{RELEVANT LITERATURE}

This section reviews the literature on the central issues identified for investigation such as teacher 
education, student-teacher preparation and its importance on the preparation of schemes of work, assessment and feedback.

\section{Definition of Teacher Education}

Teacher education is a program of education designed to provide individuals with training on knowledge proficiency, skills and attitudes required for one to provide quality service while teaching at any particular level. It is related to the development of teacher proficiency and competence such as and professional skills and pedagogical theories, a necessary component for good practice.

\section{Student Teacher Preparation of Professional Document}

Meador (2019) see preparation and planning being critical components of effective teaching and that lack of it thereof leads to failure. To enhance teacher development, preparation and planning of documents in a continuous manner assist in the following ways; makes one a better teacher, especially as one comes into close contact with the process, content and strategies boosts student teachers confidence and enables one acquire the mastery of content on one hand while on the other enables one to develop clear objectives, plan in advance the expected teacher and learner activities, assessment strategies aimed at determining the extent of achievement of the objectives and come into contact with required references and resources.

\section{The Role of University Supervisors}

University supervisors play an important role that is multi-faceted and complex; on one level, they are working to establish links and working relationships between the university and the school while on a deeper level maintaining the integrity of the teaching profession. The supervisor performs a vital role in professional learning by offering support and assessment to student teachers in the tasks and activities before them. Cornu (2015) describes a list of tasks performed by supervising teachers, such; as provide opportunities for pre-service teachers to complete the professional learning tasks and activities as outlined in the information, and guidelines booklet for the given placement and provide feedback on the pre-service teacher's practices using the focus areas, areas of strength, weakness and need for improvement.

Koc (2008) sees the role of supervisors being to check and make corrections where necessary on the professional documents intended to be used and to assess whether the prepared documents are as per the pre-established teacher performance standards. Research on supervisors' feedback shows that; it promotes thinking and reflection; (Black, Harrison, Lee, Marshall and William, 2002; Hattie and Timperley (2007) cite Hattie (2003), provide information about performance and how it can be done effectively. Through this student, teachers will be informed of their progress.

\section{Supervisors' Response on Preparation of the Scheme of Work}

University supervisors' response on student-teacher preparation of the scheme of work is of importance in the following ways; forms part of the assessment, an essential portion of determining the level of preparedness and a guide to determine the extent to which student-teacher has acquired and can apply knowledge, skills and disposition necessary to achieve learning objectives set (Taras, 2005)

\section{Impact of University Supervisor's Remarks}

The impact of supervisors' remarks on the preparation of professional documents is a critical foundation towards effective teaching. Ong'ondo and Borg (2011) aver that apart from student teachers being offered an opportunity to develop pedagogical reasoning skills, supervisors' main role of feedback is to facilitate assessment. This agrees with Bailey (2006), who points out that a supervisor promotes the reflective practice, socializes the novice into the professional discourse community and assess by providing feedback, a key factor influencing student-teacher effectiveness of the practical application of teaching skills (Tanak, 2013).

\section{METHODOLOGY}

\section{Research Design and Data Collection}

The study was based on a constructivistinterpretivism paradigm where reality is constructed through interaction between researcher and research 
subject. Based on this, the study adopted a qualitative approach where its help was based on the essence of things as they are (Gall \& Borg, 2007). The research design was a descriptive survey study that aligned itself on document analysis with a view of identifying insights when studying phenomena.

\section{Study Area}

The area of the study comprised of selected teaching practice zone in a public university

\section{Sample Size and Sampling Techniques}

The target population was third-year students in the School of Education taking Bachelor of Education Degree who were in progress but posted for teaching practice (as per the requirements) in several schools within the selected zone and their supervisors. The sample size for the study included from eight supervisors attached to assess students in the selected zone, four (4) supervisors' responses were used from the Lesson Observation Forms (LOFs) were randomly picked to obtain data from the total LOFs and from which $30 \%$ rule of thumb was applied. Similarly, from the forty LOFs from each supervisor, a sample was used to represent the larger group.

\section{Data Collection}

The data was collected by using documentary reviews and content analysis. Documentary evidence was used to support the study.

The study relied on the LOFs approved for use by the University management and given to the supervisors for use during teaching practice (Appendix 1). The rationale of using the documents analysis would enable interpretation by tracking and establishing the situation as it were. Where contradictions would arise, documents would be used to corroborate findings.

Using thick descriptions, the researcher employed a constructivist perspective in order to contextualize the situation as it were. This approach enabled the researcher to understand in detail the supervisors' responses on the preparation of professional documents.

The data analysis was approached in three stages; first, the data were categorized, sorted and coded and finally taking down the responses. From the sampled responses, each supervisor's response was placed in its own category. Secondly, responses on the developed schemes of work were teased out and recorded for the first four weeks into the session. Thirdly, categorization into themes produced data that was presented qualitatively.

\section{Validity and Reliability of the Instruments}

The study utilized the LOFs as a basis for research, where the written responses gave the voice of the supervisors. To determine validity, the research questions were developed to guide the study and it was posted to senior colleagues from the department for review and their input considered.

To determine the reliability of the instruments, filled LOFs from a nearby zone was utilized to ascertain whether what was collected had any similarity with what was used in the selected zone. Though determining validity and reliability has remained in doubt, it is important that stability and quality of the data are obtained which in this case it was collected from the university's official document.

\section{RESULTS OF THE STUDY}

Objective one: To examine the schemes of work prepared by student teachers during teaching practice. The selected sample schemes of work (Appendix 1).

Objective two: To determine the supervisor's response on prepared schemes of work.

On preparation of the schemes of work (SOW), the following themes on responses were identified; prepared, available and complete (PAVC); prepared, available but incomplete (PAVI), prepared and not available (PNAV) and prepared available with some anomalies (PAWAN).

- On prepared, available and complete (PAVC). Supervisors identified the effective use of the template where all components were adequately filled. The supervisor's remarks included; very good work, keep it up! Excellent! Well done! and up-to-date.

However, concerns raised included 'being behind schedule by one, two- or three-weeks supervisor's 
response included: "explain why you are grossly behind or show the disconnect and from this account for students' time; make-up and/or provide strategies to catch up, bridge the gap, organize for extra time to make-up, take your work seriously."

Also noted, among other concerns, a gap between what had been planned for on the lesson plan and what was expected to be covered did not match. Supervisor's remark "an explanation on why the student-teacher did not follow the SOW"; the use of a different format of the SOW where the column on references indicated authors. Suggested response "use of Official University provided template."

- On prepared and available but incomplete (PAVI), two categories were found. One was incomplete where the documents had been developed few weeks from the beginning of term and as well as the filling of columns. The supervisor's response on this was, "what reasons do you have not to have completed your work?"

- On incomplete filling of columns, noted was incomplete administrative details; teaching and learner activity not matching, assessment strategies selected did not match the teacher learning activity. The supervisor's response on this was "fill up the administrative column, indicate the subject and class, ensure teacher activity matches the student activity (depending on the task provided) and complete your work as expected."

In the assessment column, an assignment was provided (For example, EX 3.3, page 18, KLB Maths. The supervisor's reaction towards this was to "indicate the type of assessment strategies you intend to employ during the lesson, for example, oral questions, class exercisel test, quiz or short answer question." From the supervisor's response, "the expectation is the use of diagnostic or formative assessment and either uses other formative (internal, informal etc.) strategies."

- On prepared and not available (PNAV), student teachers alluded he/she prepared but was unable to present at that time, citing he/she had forgotten it. When asked to go for it, the studentteacher did not come back.
Supervisors' remarks on this, and attention is drawn to area coordinator was "I have noted with concern student-teacher X, who when asked to present the professional document and did not even after being given time to go for it. It is very disappointing and I am concerned."

- Prepared complete and available with some anomalies (PAWAN); on this some anomalies were noted on completed SOW.

- On the objectives, the development of clear objectives provides a pathway to successful instruction. Guidance on the writing of the objectives is; Specific, Measurable, Attainable, Realistic, and Time-bound (SMART) and in line with the Blooms Taxonomy. The following are samples of objectives.

Example 1: By the end of the lesson, the learner should be able to i) list the sources of information in modern times; ii) discuss how any one of the sources is used to acquire information iv) to watch a video and identify modern forms of communication. Supervisors' comments it was "fairly well prepared."

Example 2: By the end of the lesson, the learners should be able to know or tell the importance of a school library. Supervisors' response was that the "know' or 'tell' aspects are not measurable."

- The teaching and learning activities column. Proper selection of teacher activities guides the learner activities. For example, the teacher asks questions while students answer questions and/or provide instruction/students follow instruction give (in case of practical subjects), explaining, exposition, etc. Supervisors' comments on this included "provide explicit activities both from the teacher and the learner who should be commensurate."

- In the reference section, a student wrote the resources supervisor's response on this "what is the difference between references and resources?"

- On assessment, there was a misunderstanding between what an assessment meant as some student teachers wrote as a class test, quiz or short answer question. From the supervisors' 
comments, "the expectation first use of diagnostic or formative assessment used during the lesson and either use other formative (internal, informal etc.) where applicable and to test their understanding by the use of quick class quiz oral questions may be used."

From the above concerns, the effectiveness of any instruction is based on developing well thought out professional documents.

\section{CONCLUSION}

Teaching is, in essence, about helping pupils to learn which requires careful thinking about what it is exactly what a teacher wants students to learn and how best to enable the students to achieve. This intention begins with accessing the syllabus from which a scheme of work is developed. The SOW will be, among other things: - give an overview of the total course content, provide for a sequential listing of learning tasks, show a relationship between content and support materials and provide a basis for long-range planning, training and evaluation.

To be able to develop a workable scheme of work, the following ought to be considered; understanding the syllabus in terms of its content and the logical teaching order arrangement and in relation to other subjects, the reference and resources materials to be used for planning and estimated time to be used to cover the expected content.

Where student teachers have internalized the preparation of the schemes of work, the benefits accrued are enormous among other makes teaching both systematic and orderly; enables the teacher to budget for time wisely giving room for events and activities which might interfere with the school calendar; gives the teacher an insight to teaching such as to identify content, methods and relevant instructional materials and guides the teacher in making a lesson plan. Based on the above, training a student-teacher to acquire knowledge and skills used to prepare a scheme of work is necessary

The results of the study showed that student teachers' preparation of the scheme of work was not uniform. While other student teachers were able to develop a well-presented scheme of work, others were unable to present the expected as per the requirements offered during training. Others even owned up that they personally did not prepare but either copied from the commercially available scheme of work or even borrowed their friends who had prepared. Another casing point was the unavailability of the syllabus and textbooks in the schools where they were posted and even other resource materials to be used. Anomalies noted specifically were on filling of the components which failed to show a relationship between one and another.

It is from this study that gaps in preparation of the scheme of work deserve some attention because preparation of the document informs the current and future preparation of the lesson plans and classroom instruction. Where this is compromised, the whole process is likely to be compromised too.

\section{Recommendation}

A similar study on supervisor's response on the preparation of the scheme of work in other public universities and with different cohorts is recommended so as to determine their experiences. With this, the status will determine the trend, which will inform the need for change or for improvement and a move towards ensuring quality education is provided.

\section{REFERENCES}

Bailey, K. M. (2006). Language teacher supervision: A case-based approach. New York, Cambridge University Press. http://dx.doi.org/1 0.1017/CBO9780511667329

Black, P., Harrison, C., Lee, C., Marshall, B., \& Wiliam, D. (2002). Working inside the black box. London. Kings College.

Bandura, A. (1971) Social Learning Theory: General Learning Press Madison Avenue; New York

Bishop, G. (1985). Curriculum Development: A textbook for students. Longman Group UK Limited

Borko, H., \& Livingston, C. (1989). Cognition and Improvisation: Differences in mathematics instruction by expert and novice 
teachers. American educational research journal, 26(4), 473-498.

Cochran-Smith, M., Villegas, A. M., Abrams, L., Chavez Moreno, L., Mills, T., \& Stern, R. (2016). Research on teacher preparation: Charting the landscape of a sprawling field. Handbook of research on teaching, 5, 439547.

Copland, F. (2010). Causes of tension in postobservation feedback in pre-service teacher training: An alternative view. Teaching and Teacher Education, 26(3), 466-472. http://dx.doi.org/10.1016/j.tate.2009.06.001

European Commission. (2013). Supporting teacher competence development for better learning outcomes. European Commission.

Gall, M \& Borg, W.R (2007). Educational Research. An introduction. $4^{\text {th }}$ ed. New York. Longman

Gitomer, D. H., \& Zisk, R. C. (2015). Knowing what teachers know. Review of Research in Education, 39(1), 1-53.

Hall, T. J., \& Smith, M. A. (2006). Teacher planning, instruction and reflection: what we know about teacher cognitive processes? Quest, 58(4), 424-442.

Hattie, J \& Timperley, H (2007) The power of feedback. Review of Educational Research, 77 (1), $81-112$

KIE, (2006) Ministry of Education Secondary History and Government: Teachers Hnadbook; Kenya institute of Education, Nairobi

Koc, E.M. (2008). An investigation of co-operating teachers' roles as mentors during the teaching practicum at distance BA program in ELT at Anadolu University Open Education Faculty. Unpublished diss., Anadolu University, Eskiehir.

Le Cornu, R. (2015). Key components of effective professional experience in initial teacher education in Australia. Australian Institute for Teaching and School Leadership, Melbourne.
Meador (2019) Strategies for Teachers: The Power of Preparation and Planning https://www.thoug htco.com/power-of-preparation-and-planning3194263

Ong'ondo, C.O and Borg, S (2011) 'We teach plastic lessons to please them; the influence of supervision on the practice of English language student teachers in Kenya. Language teaching Research. 15(4), 509-528

Tanak, A (2013) The Development of Preservice Teachers' Teaching Practice Through Reflective Process. Official Conference Proceedings. The Asian Conference on Education 2013

Taras, M. (2005) Assessment, Summative and Formative: Some theoretical Reflections. British Journal of Educational Studies Vol. 53 (4) pg 466-487

Tatto, M. T., Peck, R., Schwille, J., Bankov, K., Senk, S. L., Rodriguez, M., ... \& Rowley, G. (2012). Policy, Practice, and Readiness to Teach Primary and Secondary Mathematics in 17 Countries: Findings from the IEA Teacher Education and Development Study in Mathematics (TEDS-MM). International Association for the Evaluation of Educational Achievement. Herengracht 487, Amsterdam, 1017 BT, The Netherlands.

Westerman, D. A. (1991). Expert and novice teacher decision making. Journal of teacher education, 42(4), 292-305. 